\title{
Análise Comparativa dos Retornos Efetuados e Estimados de Ações de Empresas Brasileiras
}

\author{
Comparative Analysis of Realized and Estimated Returns on Shares of Brazilian Companies
}

\author{
Análisis Comparativo de los Rendimientos Efectuados y Estimados de Acciones de Empresas \\ Brasileñas
}

\author{
Kascilene Gonçalves Machado ${ }^{1}$
}

\section{Resumo}

Este trabalho tem por objetivo verificar se valores estimados com os modelos propostos pelos autores Sharpe (1964) e Fama e French (1993) e 2015a) são eficientes para orientar os investidores. Para alcançar o objetivo proposto, realizou-se uma analise comparativa dos retornos efetuados e estimados das ações de 60 empresas brasileiras, no período de 2000 a 2018 , através do cálculo das variações entre os retornos reais e estimados, identificando-se se os retornos realizados são próximos dos calculados. O trabalho mostra-se relevante, pois o estudo realizado testou e verificou se os modelos de precificação de ativos, clássicos da literatura de finanças, realmente são eficientes e devem ser utilizados pelos investidores como ferramenta de apoio a tomada de decisão em renda variável. A partir dos resultados da pesquisa, é possível responder quais modelos tendem a ser mais confiáveis e quais os cuidados que os investidores devem ter ao fazer uso desses modelos. Além disso, o artigo visa a preencher a lacuna de pesquisa sobre a eficiência dos modelos de precificação de ativos no mercado acionário brasileiro, abrangendo tanto uma quantidade maior de ações a serem analisadas quanto um período de pesquisa mais amplo, o que agrega diversos cenários econômicos (expansão, estagnação, crises econômicas e recessão). Os resultados obtidos a partir de análise comparativa dos retornos reais e estimados empregando o modelo de precificação de ativo de Sharpe (1964) e o modelo de três e cinco fatores proposto por Fama e French (1993) e (2015a) indicam que apenas um pequeno percentual dos retornos calculados ocorreu conforme os retornos efetuados no período de análise, o que evidencia que tais modelos devem ser empregados com outras ferramentas para apoio de decisão em investimentos em renda variáveis.

Palavra-chave: Modelo de precificação de ativos; Modelo 3-Fatores de Fama e French; Modelo 5-Fatores de Fama e French; risco-brasil; ações.

\begin{abstract}
This work aims to verify if the values estimated with the models proposed by the authors Sharpe (1964) and Fama and French (1993) and (2015a) are efficient to guide investors. To achieve the proposed objective, we perform a comparative analysis of the realized and estimated returns of the shares from 60 Brazilian companies, in a period from 2000 to 2018, by calculating the variations between real and estimated returns, identifying if returns are close to those calculated. The work proves to be relevant, as the study carried out tested and verified the asset pricing models, classics in the finance literature, which are efficient and should be used by investors as a tool to support decision making in equity. From the results of the research, it is possible to answer which models can be more reliable and what care investors should take to use these models. Besides, the article aims to fill a research gap on asset pricing models in the Brazilian stock market, covering a larger number of shares to be analyzed during a broader research period or aggregating several economic programs (expansion, stagnation, economic crises, and recession). The results obtained from a comparative analysis of the real and estimated returns using Sharpe's asset pricing model (1964) and the three and five factors model proposed by Fame and French (1993) and (2015a) indicate that only a small percentage of calculated returns occurred according to the returns made in the analysis period, which shows that such models must be used with other tools to support decision making in variable income investments.
\end{abstract}

Keywords: Asset pricing model. Model 3-Fame and French Factors. Model 5-Fame and French Factor. brazil risk. actions. 


\section{Resumen}

El objetivo de este trabajo es verificar si los valores estimados con modelos propuestos por los autores Sharpe (1964) y Fama y French (1993) y (2015a) son eficientes para orientar los inversores. Para lograr el objetivo propuesto fue realizado un análisis comparativo de los rendimientos efectuados y estimados de las acciones de 60 empresas brasileñas, en el período de 2000 a 2018, por el cálculo de las variaciones entre los rendimientos reales y estimados, identificando si los rendimientos realizados están cerca de los calculados. El trabajo se mostró relevante, ya que el estudio realizado testó y verificó si los modelos de política de precios de activos, clásicos de la literatura de finanzas, realmente son eficientes y deben ser utilizados por los inversores como herramienta de apoyo a tomas de decisiones en ingreso viable. A partir de los resultados de la investigación, es posible responder cuales los modelos tienden a ser más fiables y cuáles son los cuidados que los inversores deben tener al usar estos modelos. Además de eso, este trabajo objetiva rellenar el hueco de investigación sobre la eficiencia de los modelos de política de precio de activos en el mercado accionario brasileño, abarcando tanto una cantidad mayor de acciones a ser analizadas cuanto un período de investigación más amplio, lo que incluye diversos escenarios económicos (expansión, estagnación, crisis económicas y recesión). Los resultados obtenidos a partir de análisis comparativo de los retornos reales y estimados empleando el modelo de política de precio de activo de Sharpe (1964) y el modelo de tres y cinco factores propuesto por Fame y French (1993) y (2015a) indican que solo un pequeño porcentual de los rendimientos calculados ocurrió según los rendimientos hechos en período de análisis, lo que evidencia que tales modelos deben ser empleados con otras herramientas para apoyo de decisión en inversiones en renta variables.

Palabras clave: Modelo de política de precio de activos. Modelo 3-Factores de Fama y French. Modelo 5-Factores de Fama y French. riesgo brasil. acciones.

\section{Introdução}

O número de investidores, inclusive de pequeno porte, vem aumentando significativamente no mercado de capitais. Os investidores têm a opção de aplicar recursos financeiros tanto no mercado de renda fixa quanto no mercado acionário. D'Avila (2019) relata que, com taxas de juros mais baixas e o mercado de ações em alta, no mês de abril registraram-se dois recordes para o mercado financeiro, pois tanto a bolsa de valores quanto o Tesouro Direto registrou a marca do primeiro milhão de investidores pessoas físicas. Segundo informações divulgadas pelo Ministério da Economia (2019), o número de investidores no Tesouro Direto teve acréscimo de 286.682 pessoas nos primeiros seis meses de 2019 , totalizando 1.072 .990 de cidadãos com investimentos ativos no programa, o que representa um aumento de $36,46 \%$ em relação ao semestre anterior. Já o número de pessoas com ações na Bolsa de Valores passou para 1,4 milhão em setembro de 2019, um aumento de 72,20\% em relação ao ano anterior (Brasil Bolsa Balcão [B3], 2019).

Como consequência dos baixos rendimentos obtidos com os investimentos atrelados a taxas de juro, os investidores são motivados a investir em ativos mais arriscados, por exemplo, em ações, com o intuito de conseguir maior retorno. Devido à facilidade em abrir conta em uma corretora, a compra de ações tornou-se um procedimento fácil e acessível a todos os investidores. No entanto, por causa da grande quantidade de informações e ações disponível no mercado, a decisão de quais papeis adquirir torna-se uma tarefa complexa, principalmente para o pequeno investidor.

A literatura de finanças propõe diversos modelos que podem ser empregados com o objetivo de calcular e analisar produtos disponíveis no mercado de capitais. Um deles é o modelo de precificação de ativos (CAPM), que permite precificar o retorno exigido de um determinado ativo, proposto por Sharpe em 1964. O CAPM descreve a relação entre o retorno requerido e o risco não diversificável da empresa. O risco de um ativo é mensurado pelo coeficiente beta $(\beta)$. Quanto maior o risco, maior o retorno exigido pelo investidor.

O modelo CAPM foi aplicado por diversos autores com o objetivo de averiguar sua capacidade de determinar os retornos das ações. Os autores Bajpai e Sharma (2015), Black, Jensen, e Scholes (1972), Damodaran (2012) e Noda, Martelanc, e Kayo (2016) concluíram que o modelo cumpre bem sua função. Já os autores Fama e French (1992), Lakonishok e Shapiro (1986), Nyangara, Nyangara, Ndlovu, e Tyavambiza (2016), Scott (2009) relataram em suas pesquisas que o CAPM não reflete os retornos das ações, visto que os resultados obtidos pelos autores indicaram que os valores obtidos nos cálculos dos retornos estimados, ao empregar o modelo CAPM, divergiram significativamente dos retornos reais. De acordo com os autores, o CAPM determina o fator risco de mercado como responsável por explicar os retornos exigidos pelos investidores, entretanto apenas um fator é insuficiente para explicar o retorno das ações.

Após os resultados ineficientes obtidos com o empego do CAPM, Fama e French (1993) propuseram um modelo de precificação com três fatores: risco de mercado, tamanho e índice B/M. Rayes, Araújo, e Barbedo (2012) relatam que esses fatores adicionais estão empiricamente fundamentados nas observações de que a média histórica dos retornos de empresas pequenas e de ações com alta razão entre o valor contábil e o valor de mercado são maiores do que previstos pelo CAPM.

Para tornar o modelo de precificação mais robusto, Fama e French (2015a) incorporaram novas variáveis ao modelo de três fatores, resultando em um novo modelo, denominado de CAPM de cinco fatores. As variáveis acrescentadas foram lucratividade e investimentos. 
O modelo tradicional de CAPM, desenvolvido por Sharpe (1964), também foi aplicado no trabalho de Cunha (2011), o qual adicionou o prêmio pelo risco-país, como mais uma alternativa de estimar os retornos das ações.

Considerando os diversos modelos de precificação e suas especificidades, este trabalho tem por objetivo verificar se os resultados obtidos com os modelos propostos pelos autores Sharpe (1964) e Fama e French (1993) e (2015a) são eficientes para orientar os investidores na tomada de decisão em renda variável. Para alcançar o objetivo proposto, é realizada uma análise comparativa dos retornos das ações efetivados no período de 2000 a 2018, com os retornos calculados e estimados a partir do modelo de precificação (CAPM) com um fator, três e cinco fatores, além de analisar o modelo de precificação com o riscoBrasil. A partir desta pesquisa é possível verificar qual(is) modelo(s) é(são) mais adequado(s) para mensurar os retornos das ações no mercado brasileiro e se, de fato, um(alguns) desses modelos pode $(\mathrm{m})$ ser empregado(s) pelos investidores como ferramenta de apoio à tomada de decisão em investimentos em renda variável.

\section{Referencial Teórico}

\subsection{Modelo de precificação de ativos}

O modelo de precificação de ativos (Capital Asset Pricing Model - CAPM) descreve a relação entre o retorno requerido e o risco não diversificável da empresa. O risco de um ativo é mensurado no CAPM pelo coeficiente beta (ß). (Assaf Neto \& Lima, 2014).

$$
R_{e}=R_{f}+\beta\left(R_{M}-R_{f}\right)
$$

Em que $R_{e}$ é a taxa mínima de retorno requerida pelos acionistas; $R_{F}$ é a taxa de retorno de ativos livres de risco; $\beta$ é o coeficiente beta, medida do risco sistemático (inclinação da reta de regressão), e $R_{M}$ é a rentabilidade da carteira de mercado (índice do mercado de ações).

No modelo CAPM, a taxa de retorno requerida pelo investidor deve incluir a taxa livre de risco da economia mais um prêmio que remunere o risco sistemático apresentado pelo ativo em avaliação e representado pelo coeficiente beta. $A$ diferença entre o retorno da carteira de mercado e a taxa de juros definida livre de risco $\left(R_{M}-R_{F}\right)$ é o prêmio pelo risco de mercado. Esse prêmio, ao ser alavancado pelo beta do ativo, reflete o risco de mercado ajustado ao ativo em avaliação.

O CAPM tem amplo emprego no mercado de capitais, auxiliando na tomada de decisão em condições de risco, visto que o modelo permite mensurar a taxa de retorno requerida pelos investidores, em que o coeficiente beta indica o acréscimo necessário no retorno de um ativo de modo a remunerar o risco sistemático, ou seja, quanto maior o risco, maior o retorno exigido pelo investidor.

Soranco, Cruz, Zanin, e Rocha (2013) empregaram o modelo CAPM para identificar, entre nove ações selecionadas do Índice Bovespa, os ativos subvalorizados, indicados como opção de compra, e os ativos supervalorizados, indicados como opção de venda, no período de janeiro de 2007 a dezembro de 2012. Os resultados da pesquisa apontaram que cinco papéis estavam supervalorizados e quatro subvalorizados na relação risco x retorno proporcionado.

Miralles-Quirós, Miralles-Quirós, e Gonçalves (2017) desenvolveram um estudo com o objetivo de analisar se a Bovespa é um mercado eficiente utilizando o CAPM, em que aplicaram uma estratégia de investimento intuitiva baseada na compra exclusiva das ações consideradas subavaliadas pelo CAPM, e compararam com a estratégia passiva de todas as ações que compõem o índice seletivo. Com a pesquisa, os autores concluíram que os dados são consistentes com a eficiência do mercado, bem como com o CAPM.

Apesar da grande aplicabilidade do CAPM, o modelo proposto por Sharpe (1964) é baseado em algumas hipóteses: (i) os ativos apenas remuneram o risco não diversificável; (ii) os investidores têm expectativas homogêneas em relação aos retornos esperados e à variação dos retornos; (iii) é possível investir e captar recursos à taxa livre de risco em quantidades ilimitadas; (iv) ausência de imperfeições de mercado; v) os investidores são racionais e tomam decisões apenas em termos de retornos esperados e risco de ativos; (vi) os investidores têm aversão ao risco, selecionando entre dois portfólios com o mesmo retorno esperado aquele com o menor risco.

Tais premissas dificultam o uso do modelo para tomada de decisão, pois as suposições não são condizentes com o mercado real. Além disso, os autores Stambaugh (1982) e Fama e French (1992) questionam em seus trabalhos se o retorno de uma ação pode ser explicado somente por uma variável, no caso, o parâmetro beta. Scott (2009) concluiu também que o modelo CAPM não consegue determinar o retorno dos ativos.

Devido às limitações do CAPM, Fama e French (1993) propuseram um modelo de três fatores com melhor capacidade de precificação dos retornos das ações.

\subsection{0 modelo de três fatores de Fama e French}

Eugene Fama e Kenneth French, em 1993, desenvolveram um novo modelo de precificação de ativos, baseado no modelo CAPM, o modelo de três fatores de precificação de ativos (FF3F): risco de mercado, tamanho e índice B/M. 
No modelo-base FF3F, a explicação para o retorno de uma ação é atribuída aos seguintes fatores: risco de mercado, tamanho e valor. De acordo com os autores, os fatores tamanho e valor (ou índice 'book-to-market', B/M, a razão entre os valores contábil de mercado de determinada empresa) capturavam parte significante do retorno das ações listadas no mercado acionário americano que não era explicado por outros elementos atribuídos em diferentes modelos comumente utilizados.

Matematicamente, o modelo de três fatores pode ser expresso por (2):

$$
R_{e}=R_{f}+\beta\left(R_{M}-R_{f}\right)+S M B+H M L
$$

Em que $R_{e}$ é a taxa mínima de retorno requerida pelos acionistas; $R_{F}$ é a taxa de retorno de ativos livres de risco; $\beta$ é o coeficiente beta, medida do risco sistemático (inclinação da reta de regressão), e $R_{M}$ é a rentabilidade da carteira de mercado (índice do mercado de ações), SMB é o prêmio pelo fator tamanho (Small Minus Big ou a diferença entre a média de retorno das ações de empresas de pequeno porte e média de retorno das ações de empresas de grande porte); HML é o prêmio pelo fator VC/VM (High Minus Low ou diferença entre a média de retorno das ações com alto índice de valor contábil sobre valor de mercado e a média de retorno das ações com baixo índice de valor contábil sobre valor de mercado).

O modelo proposto foi aplicado pelos autores no mercado americano para explicar o retorno das ações das empresas listadas na New York Stock Exchange (NYSE), American Stock Exchange (AMEX) e National Association of Securities Dealers (Nasdaq). Os resultados obtidos por Fama e French (1993) nesses testes permitiram concluir que os coeficientes da equação indicada acima se mostraram simultaneamente significantes, indicando a força estatística e a validade do modelo.

Rayes, Araújo, e Barbedo (2012) testaram o modelo de três fatores de Fama e French (1993) no mercado acionário brasileiro, no período de julho de 2000 a junho de 2008, com o objetivo de identificar se os fatores prêmio de mercado, SMB e HML explicam os retornos das ações no Brasil, cujas amostras foram compostas por ações individuais e agrupadas em carteiras com as quarenta empresas de maior liquidez na bolsa de valores de São Paulo no ano de 2004, e concluíram que, para as ações individuais e para as carteiras, os fatores SMB e HML não foram significativos.

Malaga e Securato (2004) empregaram a mesma metodologia desenvolvida e aplicada por Fama e French (1993) nas ações listadas na B3 no período 1995-2003. Os resultados observados indicaram que o modelo de três fatores é superior ao CAPM na explicação dos retornos das ações da amostra utilizada, e que os três fatores são significantes, complementando-se na explicação dos retornos de ações de diferentes características.

O modelo de três fatores também foi empregado no trabalho de Argolo, Leal, e Almeida (2012) para verificar as estimativas do custo de capital acionário no período de julho de 1995 a junho de 2007, e os resultados obtidos indicaram divergências entre os valores reais e estimados, demonstrando que o uso do modelo de Fama e French (1993) para estimar o custo de capital acionário no Brasil não é eficiente. Além disso, os autores relataram que a complexidade de se estimar mais dois fatores não acompanham valores intuitivamente aceitáveis do custo de capital acionário na maioria dos casos.

Rogers e Securato (2009) testaram e compararam o modelo CAPM de Sharpe e o modelo de três fatores de Fama e French, alternativos para predição de retornos esperados no mercado de capitais brasileiro. Os resultados demonstraram que o modelo de três fatores de Fama e French tende a explicar os retornos futuros, mas o fator que capta o efeito book-to-market não se mostrou significativo. Dessa forma, os autores concluíram que a predição de retornos esperados no mercado de capitais brasileiro pode ser realizada por um modelo de dois fatores: um que capta o excesso de retorno do mercado e outro que capta o efeito do tamanho da firma.

A partir do modelo FF3F, outros fatores que pudessem complementar, ou explicar, os retornos das ações foram implementados. Fama e French (2015a) decidiram, portanto, incluir dois novos fatores -'lucratividade' (RMW) e 'investimento' (CMA). Os autores comparam-no com o antigo modelo FF3F, e atestam a superioridade da nova versão através dos menores valores apresentados pelos interceptos, indicando que mais dos retornos pode ser, agora, explicado.

\subsection{O modelo de cinco fatores de Fama e French}

Fama e French (2015a) reestruturaram o modelo FF3F, acrescentando dois fatores, lucratividade e investimento, obtendo um novo modelo denominado de modelo de cinco fatores de precificação de ativos (FF5F). Com a adição das variáveis lucratividade e investimento, tem-se o modelo de cinco fatores, expresso pela equação (3):

$$
R_{e}=R_{f}+\beta\left(R_{M}-R_{f}\right)+S M B+H M L+R W M+C M A
$$

O fator RMW é calculado a partir da lucratividade operacional aferida pela companhia. O índice financeiro que possibilita esse cálculo é a relação lucro operacional/PL. Logo, o fator mede a diferença de retorno obtida por ações com desempenho operacional robusto e fraco. Já o fator de risco CMA é calculado tendo como parâmetro a variação dos ativos totais de um ano para o outro. A ideia do fator é medir a diferença de retorno entre empresas que expandiram 
com mais intensidade seus ativos totais (arrojadas) e empresas que tiveram expansão mais moderada do ativo, ou que, até mesmo, tiveram uma contração na sua posição de ativos (conservadoras) (Vieira, Maia, Klotzle, \& Figueiredo, 2017).

Os testes desenvolvidos pelos autores no mercado acionário americano mostraram que o modelo de cinco fatores explica entre $71 \%$ e $94 \%$ dos retornos esperados para as carteiras de tamanho, valor, rentabilidade e investimento. Assim, os autores concluíram que o modelo de cinco fatores, se direcionado a capturar os padrões de tamanho, valor, lucratividade e investimento nos retornos médios das ações, tem um desempenho melhor do que o modelo de três fatores (Fama \& French, 2015b).

O modelo FF5F foi aplicado no mercado acionário brasileiro no estudo de Martins e Eid (2015), para observar se seus resultados eram consistentes também no mercado nacional, especificamente na Bolsa de Valores de São Paulo (B3). Os resultados, no entanto, se mostraram apenas parcialmente em linha com os obtidos pelos proponentes do modelo nos EUA. Os novos fatores não demonstraram ser fortemente explicativos no caso brasileiro, com necessidade de outras investigações sobre os fatores lucratividade e investimentos.

Vieira et al. (2017) utilizaram o modelo de cinco fatores proposto por Fama e French (2015a) para verificar sua influência nos retornos do mercado acionário brasileiro no período de 2008 a 2015 . A classe de ativos investigada foram os retornos semanais de carteiras setoriais. Os resultados apontaram para uma importância maior do prêmio de risco atrelado aos investimentos no modelo.

\subsection{Modelo de precificação de ativos com o risco-Brasil}

Além das variáveis mencionadas e adicionadas ao modelo de precificação original (modelo de um fator), outras variáveis são comumente acrescentadas ao modelo original e aplicadas com o intuito de verificar se os retornos das ações podem ser mensurados de forma mais precisa e explicada por esse conjunto de variáveis.

Como exemplo, pode-se citar o trabalho de Silva, Trindade, Nagib, e Reina (2017) que incluíram a variável riscoBrasil ao modelo CAPM (expressão (4)) para analisar as empresas do novo mercado, no período de 2010 a 2016, com o objetivo de verificar se o acréscimo da variável risco-país torna o modelo mais eficiente na determinação dos retornos de ações em economia emergentes. Os autores concluíram que o modelo CAPM não contribui significantemente para explicar o retorno das ações, mesmo adicionado do risco-país.

$$
R_{e}=R_{f}+\beta\left(R_{M}-R_{f}\right)+\alpha_{B R}
$$

Em que $\alpha_{B R}$ é o riscoBrasil.

\section{Metodologia}

A metodologia de pesquisa empregada neste trabalho é de natureza aplicada, quantitativa e descritiva. De acordo com Cervo e Bervian (2007), a pesquisa descritiva observa, registra, analisa e correlaciona fatos ou fenômenos (variáveis), sem manipulá-los. Procura descobrir, com a maior precisão possível, a frequência com que um fenômeno ocorre, sua relação e conexão com outros, sua natureza e suas características. Neste trabalho, realizou-se uma análise comparativa dos retornos estimados (calculados) pelos diferentes modelos de precificação de ativos descritos nos itens 2.1 a 2.4 e dos retornos efetuados no mercado de empresas de capital aberto. Verificouse que os modelos abordados na literatura de finanças são eficazes na precificação dos retornos das ações no mercado brasileiro. Assim, calcularam-se os retornos estimados das ações utilizando os quatro modelos matemáticos de precificação de ativos e coletaram-se, no banco de dados do sistema Economatica, os retornos reais das ações das empresas analisadas nesta pesquisa.

\subsection{Coleta de dados}

Os dados necessários para a análise foram coletados do sistema Economatica (indicadores das empresas) e na base de dados do Instituto Assaf, (2019) (indicadores macroeconômicos). O período de pesquisa compreende os anos de 2000 a 2018. O período escolhido tenta ser o mais amplo possível, abrangendo diferentes cenários econômicos e políticos, que permitam uma análise mais aprofundada que possa identificar se há um período mais propício para tornar os modelos mais eficientes.

Faz parte da pesquisa um conjunto de 60 empresas listadas na Bolsa de Valores de São Paulo (B3). As demais empresas listadas na B3 foram excluídas da pesquisa, pois não possuíam dados suficientes para o desenvolvimento do trabalho durante o período de análise.

Observa-se que a lista contendo as empresas cadastradas na B3 possui variações ao longo do tempo. As empresas entram e saem da bolsa em períodos diferentes. Algumas se unem, criando uma nova empresa. Nesse contexto, os estudos que necessitam de dados dessas empresas, dentro de um determinado período, devem selecionar cuidadosamente as empresas que possuem todas as informações do respectivo período de pesquisa. 
Apesar da B3, atualmente, possuir um número maior de empresas cadastradas, este trabalho analisou apenas 60 empresas, pois, no período de estudo (2000 a 2018), muitas empresas abriram seu capital após o ano 2000 . Além disso, outras empresas fecharam seu capital antes do ano de 2018. Essas empresas foram excluídas da pesquisa por não possuírem todas as informações anuais durante o período almejado. Assim, somente as empresas que possuem dados anuais de 2000 a 2018 fizeram parte da pesquisa, isto é, as 60 empresas estudadas. Quanto à data inicial escolhida da pesquisa (2000), observou-se que o número de empresas a serem estudadas seria ainda mais reduzido caso a pesquisa iniciasse em anos anteriores ao ano 2000. Logo, a data inicial foi escolhida com o intuito de obter uma maior representatividade de empresas, de diferentes segmentos e setores, para a aplicação e análise dos diferentes modelos de precificação de ativos.

\subsection{Variáveis do problema}

As variáveis taxa livre de risco $\left(R_{F}\right)$, taxa de mercado $\left(R_{M}\right)$ e risco sistemático $(\beta)$ são comuns em todos os modelos. Para a taxa livre de risco adotou-se os valores da taxa Selic, taxa básica de juros da economia. Para a taxa de mercado, adotou-se o Índice Bovespa, indicador do desempenho médio das cotações das ações negociadas na B3. Já para o risco sistemático, utilizou-se o beta das empresas.

No modelo de três fatores, além das variáveis mencionadas acima, utilizou-se também os valores de mercado das empresas para compor o fator SMB, que representa a diferença entre os retornos das carteiras composta por ações de empresas. Assim, em janeiro de cada ano t, com t variando de 2000 a 2018, todas as ações da amostra formam ordenadas por valor de mercado das empresas, cujo valor mediano foi utilizado para dividir a amostra em dois grupos, classificados como B (Big) e S (Small), constituídos pelas empresas de maior e menor valor de mercado, respectivamente. Já para determinar o índice $B / M$, calculou-se a relação entre o patrimônio líquido $(P L)$ e o valor de mercado (VM), conforme expressão (5):

$$
\frac{B}{M}=\frac{P L}{V M}
$$

O modelo de cinco fatores necessita, ainda, das variáveis RMW e CMA. A RMW pode ser determinada pela relação entre o lucro operacional e o patrimônio líquido (expressão). Já o CMA é a variação do ativo total das empresas.

$$
R M W=\frac{L O P}{P L}
$$

Por fim, o modelo CAPM com risco-Brasil incorpora a variável risco-Brasil $\left(\alpha_{B R}\right)$, indicador que determina o grau de instabilidade econômica, ao modelo tradicional (CAPM de um fator).

\subsection{Montagem do problema}

Após a coleta dos dados, processou-se a substituição dos valores, nas variáveis descritas no item 3.2, para calcular e estimar os retornos das ações, de acordo com as particularidades de cada modelo.

Para cada uma das empresas analisadas, foi efetuado o cálculo dos retornos empregando os quatros modelos de precificação para cada ano do período de análise (de 2000 a 2018), além de apurar os retornos efetivados durante esse período. Em seguida, foram construídas sessenta matrizes de 19x5. As linhas das matrizes são constituídas pelos anos e as colunas, pelos retornos efetivados e estimados das ações em cada ano. Cada matriz compõe informações sobre as empresas pesquisadas.

Em um primeiro momento, foram calculadas as variações entre os retornos, sempre considerando o retorno efetivado e o retorno estimado por um determinado modelo para cada ano. Essa etapa tem por finalidade verificar se o retorno efetivado ocorreu conforme o retorno estimado, ou seja, se os retornos possuem valores aproximados. Os resultados obtidos por cada modelo foram contabilizados e analisados sob o ponto de vista da amostra total (número de anos). Assim, obteve-se o percentual de valores aproximados entre retornos efetivados e estimados. Essa análise permitiu identificar quais modelos conseguem melhor precificar o retorno das ações das empresas. Repetiu-se o procedimento para todas as empresas.

Posteriormente, elaboraram-se duas outras matrizes, uma de $60 \times 5$ e outra de $60 \times 4$. A primeira matriz é constituída pelos retornos médios efetivados e estimados durante o período de pesquisa, e a segunda matriz contém as variações médias dos retornos das ações.

Além das matrizes descritas anteriormente, diversos gráficos foram traçados para uma melhor compreensão e visualização dos resultados apurados. O item 4 descreve esses resultados. 


\section{Análise de Resultados}

\subsection{Análise comparativa entre retorno real das ações e os retornos calculados pelos diferentes modelos CAPM}

Nesta secção são apresentados os resultados da análise comparativa entre os retornos realizados das ações das empresas e os retornos calculados pelos modelos CAPM, FF3F, FF5F e CAPM com o riscoBrasil. Para realizar a comparação desses valores, efetuou-se o cálculo das variações entre o retorno realizado e os calculados. Assim, foi possível identificar se os retornos realizados eram próximos dos retornos calculados. Valores mais baixos e próximos de zero indicam que os retornos realizados ocorreram de acordo com a expectativa do investidor. Já os valores positivos indicam que os retornos realizados foram superiores aos estimados e superaram as expectativas dos investidores. Quanto maior e mais positivo os valores, maiores os retornos oferecidos pelas empresas comparados aos retornos estimados pelos diferentes modelos. Por outro lado, valores negativos indicam que o retorno realizado foi inferior ao calculado. Nessa situação, os investidores tiveram suas expectativas de ganho frustradas e, quanto maior e mais negativo o valor apresentado, menor o retorno obtido das empresas.

A análise da variação permite orientar se os modelos são capazes de precificar o retorno de uma ação e auxiliar os investidores quanto às opções de quais ações de empresas devem ser adquiridas.

Após o cálculo das variações, considerando resultados de variação entre $\pm 10 \%$, contabilizou-se a quantidade de valores dentro dessa faixa no período de análise. A Tabela 1 apresenta o percentual de valores com variação de $\pm 10 \%$ para cada um dos modelos de precificação e a quantidade de empresas que obtiveram esses resultados.

$\mathrm{Na}$ Tabela 1, a coluna "Percentual de valores com variação entre $-10 \%$ e $+10 \%$ ", apresenta o percentual considerando 19 amostras (período de análise). Assim, " $0,00 \%$ " indica que não há valores entre $\pm 10 \%$, ou seja, em nenhum dos anos analisados o retorno efetivado foi próximo ao estimado; " $5,26 \%$ ", há apenas um valor nessa faixa, isto é, em apenas um ano o retorno efetuado foi próximo ao estimado; "10,53", dois valores, ou seja, retorno efetivado e estimado próximos em dois anos; "15,79\%", "21,05\%" e "26,32", três, quatro e cinco valores, respectivamente, e, por fim, " $31,58 \%$ ", indicando uma maior quantidade de valores na faixa entre $\pm 10 \%$, com seis valores (isto é, em seis anos foi encontrado resultados de retornos estimados próximos ao retorno previsto). A pesquisa desenvolvida não obteve resultados superiores a seis anos com valores na faixa entre $-10 \%$ e $+10 \%$.

Tabela 1

Percentual de valores com variação de $\pm 10 \%$

\begin{tabular}{lcccc}
\hline Percentual de valores com variação entre $\mathbf{- 1 0 \%} \mathbf{e}+\mathbf{+ 1 0} \%$ & CAPM & FF3F & FF5F & CAPM risco-Brasil \\
\hline $0,00 \%$ & 20 & 32 & 51 & 15 \\
$5,26 \%$ & 19 & 21 & 7 & 15 \\
$10,53 \%$ & 10 & 5 & 0 & 13 \\
$15,79 \%$ & 7 & 2 & 2 & 8 \\
$21,05 \%$ & 1 & 0 & 0 & 6 \\
$26,32 \%$ & 3 & 0 & 0 & 1 \\
$31,58 \%$ & 0 & 0 & 0 & 2 \\
Total de empresas & 60 & 60 & 60 & 60 \\
\hline
\end{tabular}

Analisando cada um dos modelos, verifica-se, na Tabela 1, que o emprego do modelo FF5F não apresentou nenhum retorno estimado próximo dos retornos efetuados para 51 empresas analisadas. Além disso, para apenas sete empresas, em um único ano, de todo o período analisado, os retornos foram similares. Conclui-se, nessa analise inicial, que esse modelo não consegue precificar os retornos das ações no mercado brasileiro.

O modelo FF3F apresentou, no período analisado, três valores dentro da faixa estabelecida, mas somente para duas empresas, logo, esse modelo também não é capaz de precificar os retornos das ações.

Os modelos CAPM e CAPM com riscoBrasil apresentaram uma quantidade maior de retornos próximos, de acordo com a faixa estabelecida, no entanto esses valores ainda são baixos em ambos os modelos. Observa-se, por exemplo, que o modelo CAPM com riscoBrasil conseguiu, em duas empresas, ter valor de retorno entre o estimado e efetivado, com maior quantidade de dados, entretanto apenas seis valores próximos de um total de 19 dados analisados é pouco expressivo para considerar o modelo como eficiente na precificação do retorno das ações.

O Gráfico 1 ilustra a relação de quantidade de empresa e quantidade de valores dentro da faixa de $\pm 10 \%$ para cada um dos modelos analisados. 
Gráfico 1: Relação entre a quantidade de empresas e valores na faixa de $\pm 10 \%$

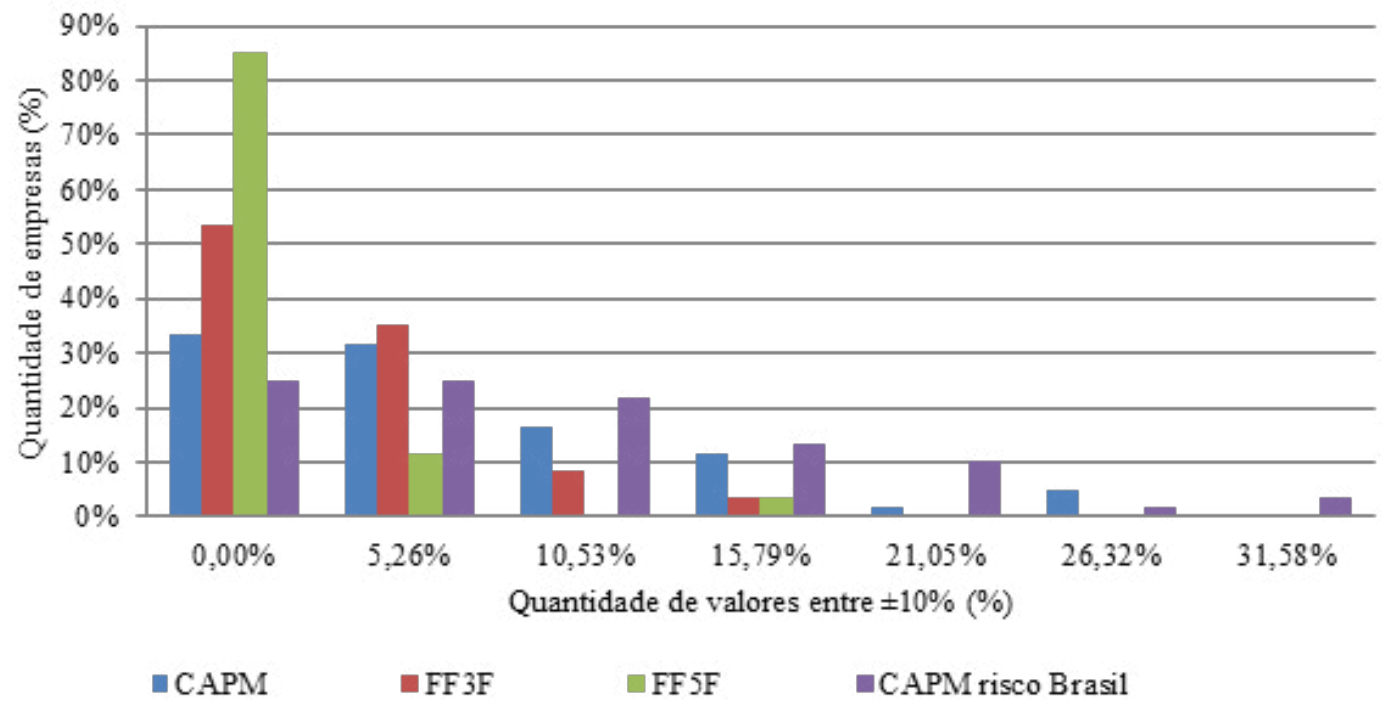

A partir do Gráfico 1, observa-se que os resultados obtidos com o modelo FF5F apontam para uma divergência entre os retornos efetivados e calculados. Quase $97 \%$ das empresas analisadas apresentaram variações dos retornos fora da faixa estabelecida ou com apenas um valor dentro dessa faixa. Já o modelo CAPM com riscoBrasil teve uma maior quantidade de variações dentro da faixa de $\pm 10 \%$. Pode-se afirmar que, entre os modelos estudados, o CAPM com riscoBrasil tende a precificar melhor os retornos das ações comparados aos demais modelos analisados.

Detalhando um pouco mais a análise das informações apresentadas no Gráfico 1, verifica-se que muitas empresas não puderam ter os retornos de suas ações mensurados conforme realidade do mercado, com destaque para o modelo de cinco fatores, em que $85 \%$ das empresas analisadas não tiveram nenhum valor aproximado entre o retorno efetivado e 0 estimado por esse modelo. O modelo de três fatores também se mostrou deficiente para mais de $50 \%$ das empresas que compõem a amostra da pesquisa. Já o modelo CAPM com riscoBrasil apresentou um menor número de empresas $(25 \%)$ em que não conseguiu precificar o retorno de suas ações de acordo com o mercado. Por outro lado, observa-se que a maior quantidade de dados (de 4 a 6 valores) com retornos aproximados foram obtidos somente pelos modelos CAPM e CAPM com riscoBrasil, sendo que o CAPM com riscoBrasil possuiu uma maior representatividade nessa análise (15\%).

Conclui-se que o modelo de precificação de ativos com riscoBrasil consegue precificar o retorno das ações mais próximo da realidade do mercado, embora o modelo também tivesse deficiências em vários dados das análises. Além disso, pode-se afirma que os modelos de três e cinco fatores não são aplicáveis ao mercado brasileiro e os resultados estimados por esses modelos não condizem com os retornos reais das ações no período de análise.

\subsection{Análise da dispersão dos dados}

Para uma melhor visualização dos dados, foram traçados gráficos das dispersões dos valores médios das variações entre os retornos efetivados e os calculados pelos diferentes modelos das 60 empresas analisadas. Os Gráficos 2, 3, 4 e 5 ilustram as dispersões dos resultados das variações calculadas.

Gráfico 2: Análise de dispersão: modelo CAPM

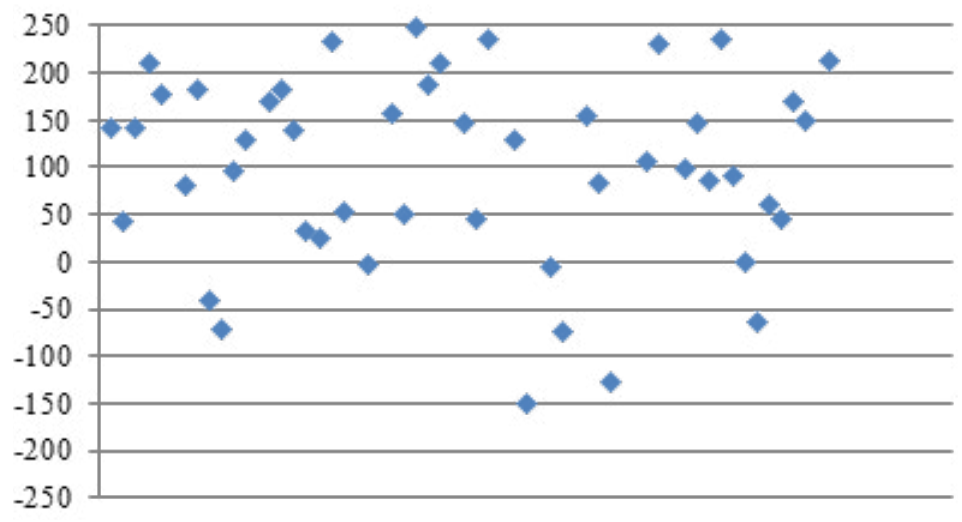


Gráfico 3: Análise de dispersão: modelo FF3F

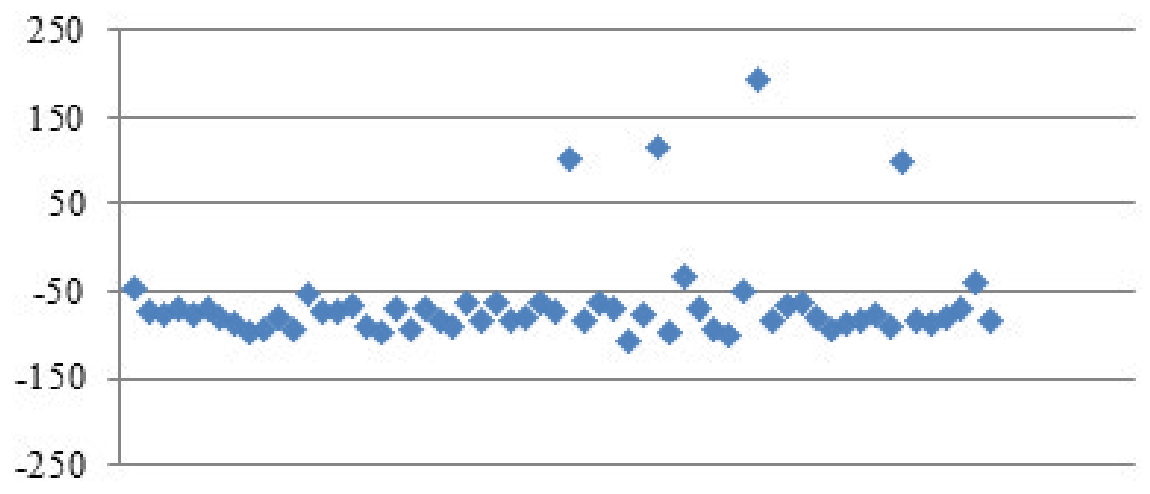

Gráfico 4: Análise de dispersão: modelo FF5F

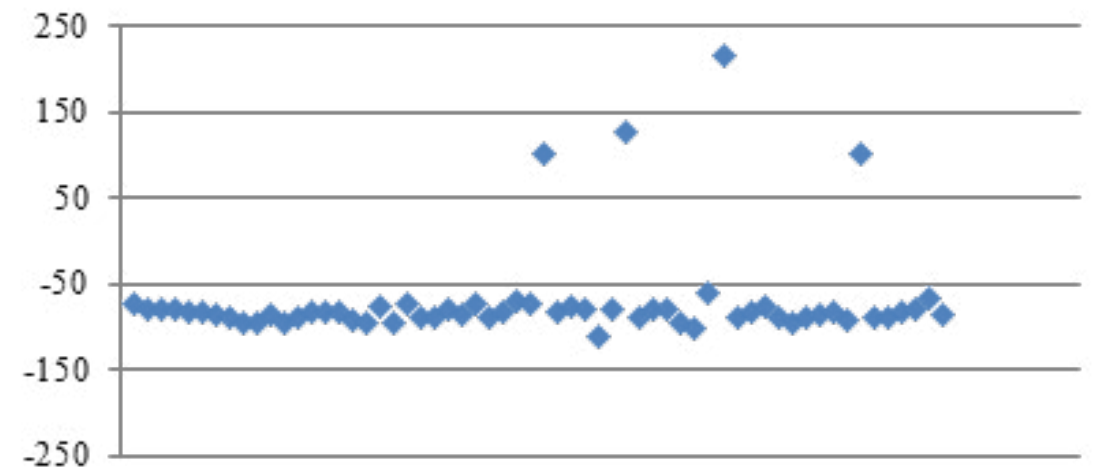

Gráfico 5: Análise de dispersão: modelo CAPM com riscoBrasil

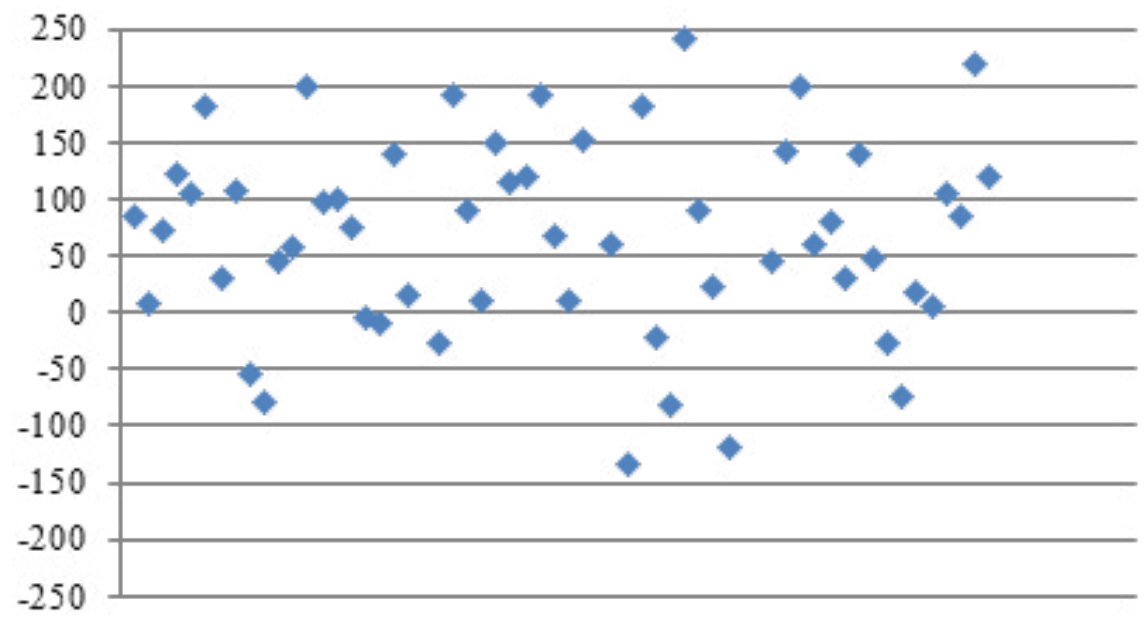

Conforme mencionado anteriormente, os dados analisados são resultado das variações dos retornos efetivados e dos retornos estimados pelos modelos. Quanto mais próximo do valor zero, mais indicado é o modelo para precificar os retornos das ações, visto que valores próximos de zero demonstram que os retornos estimados são similares aos retornos efetivados. Analisando os gráficos acima, observa-se que o Gráfico 5 (resultados obtidos empregando o modelo CAPM com riscoBrasil) é o que apresenta uma maior concentração de valores próximo ao eixo zero. Já o modelo FF5F (Gráfico 4) não apresentou nenhum valor próximo ao eixo zero, inclusive, os valores estão muito distantes, sendo a maioria inferior a $50 \%$.

Analisando os Gráficos 3 e 4, nota-se que os valores estão muito concentrados na faixa de $-50 \%$ a $-100 \%$, mostrando que ambos os modelos superestimaram os retornos das ações das empresas analisadas, ou seja, os valores estimados foram muito superiores aos realizados. Conclui-se que a inserção de novas variáveis ao modelo CAPM não contribuiu para uma melhor precificação dos retornos das ações no mercado brasileiro, ocasionandouma frustação para o investidor que emprega ambos os modelos para auxiliar na tomada de decisão de investimentos em renda variável. 
Os modelos CAPM e CAPM riscoBrasil (Gráficos 2 e 5) possuem uma quantidade maior de resultados próximo ao eixo zero, no entanto há uma grande variabilidade de informações. Essa variabilidade dos dados reduz a confiabilidade do uso dos modelos para precificar o retorno das ações, o que implica que tais modelos devem ser utilizados com ressalvas, sempre buscando alternativas para auxiliar na tomada de decisão quanto a investimentos em renda variável. Por fim, pode-se afirmar novamente que os modelos de três e cinco fatores não demonstraram resultados coerentes com os retornos realizados no mercado acionário brasileiro, o que indica que tais modelos não conseguem precificar com precisão o retorno das ações e não devem ser empregados para essa finalidade no mercado de ações no Brasil.

Em termos de retornos, a partir das matrizes dos valores médios construídos, foi possível identificar as empresas que obtiveram maiores e menores retornos médios. Assim, considerando uma amostra de 10\% do total das empresas analisadas, as seis empresas com maiores e menores retornos médios de mercado são (Tabela 2).

Tabela 2

Retornos médios

\begin{tabular}{lclc}
\hline \multicolumn{1}{c}{ Empresas com maiores retornos médios } & \multicolumn{2}{c}{ Empresas com menores retornos médios } \\
\hline Pet Manguinhos & $126,93 \%$ & Cedro & $7,87 \%$ \\
Panatlantica & $85,73 \%$ & Teka & $4,04 \%$ \\
lochp Maxion & $52,91 \%$ & Cemar & $3,25 \%$ \\
Guararapes & $46,95 \%$ & Light & $3,04 \%$ \\
Lojas Americanas & $43,88 \%$ & Oi & $-2,39 \%$ \\
Braskem & $42,79 \%$ & Itautec & $-4,57 \%$ \\
\hline
\end{tabular}

Ao aplicar os modelos de precificação para estimar os retornos das ações dessas empresas, observa-se que os valores definidos pelos modelos estão aquém dos valores efetivados. Os valores estimados por cada modelo, para cada uma das empresas listadas na Tabela 2, estão ilustrados nos Gráficos 6 e 7.

Gráfico 6: Maiores retornos médios efetivados (\%)

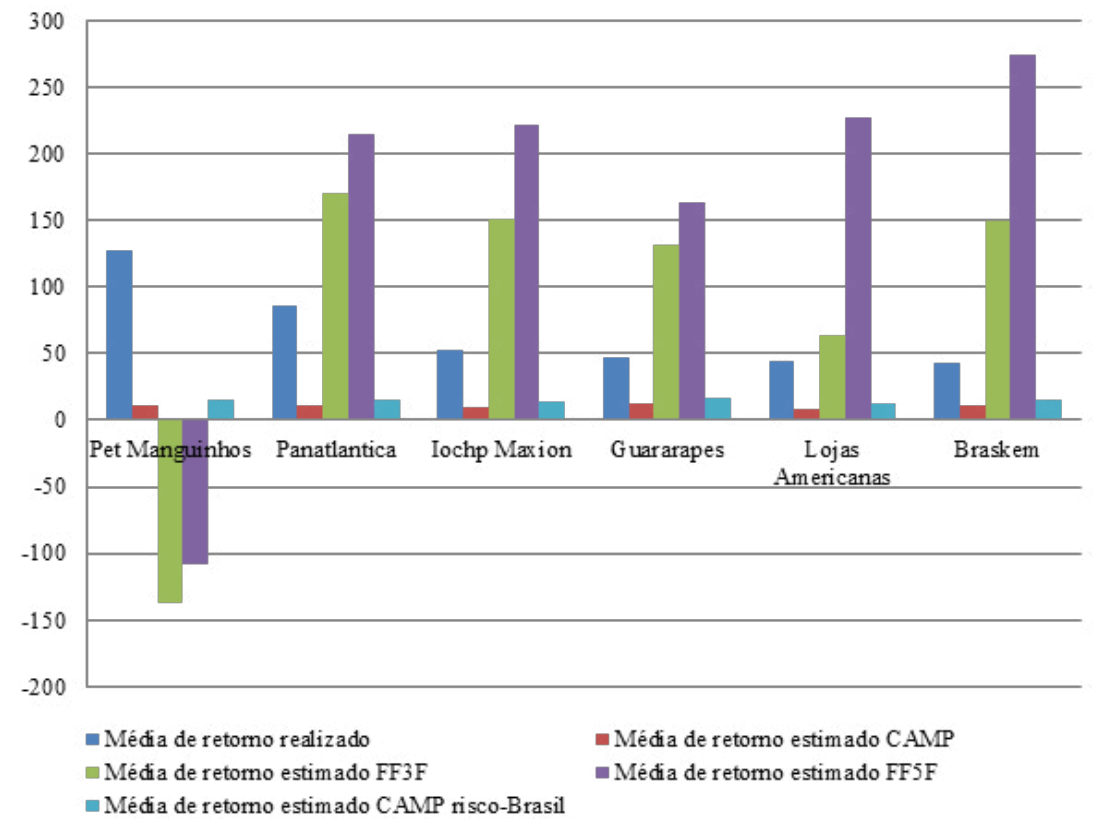

Observa-se, em ambos os gráficos, que nenhum dos modelos conseguiu precificar retornos próximos ao realizados no período de análise, com destaque para as seguintes empresas: (i) Pet Manguinhos, que apresentou o maior retorno médio comparado aos retornos médios de todas as empresas da pesquisa. Os retornos estimados pelos modelos CAPM e CAPM com riscoBrasil, foram de $10,88 \%$ e $15,02 \%$, respectivamente, enquanto os retornos estimados pelos modelos de três e cinco fatores foram negativos, indicando que as ações dessa empresa não seriam uma boa opção de investimento e (ii) Oi e Itautec, que tiveram retornos médios estimados muito superiores e positivos pelos modelos de três e cinco fatores, enquanto os retornos médios efetivados por ambas as empresas foram negativos. Os demais modelos de precificação também indicaram retornos médios positivos para essas empresas, induzindo os investidores a comprar ações das empresas com o pior desempenho entre todas as empresas analisadas. 
Gráfico 7 - Menores retornos médios efetivados (\%)

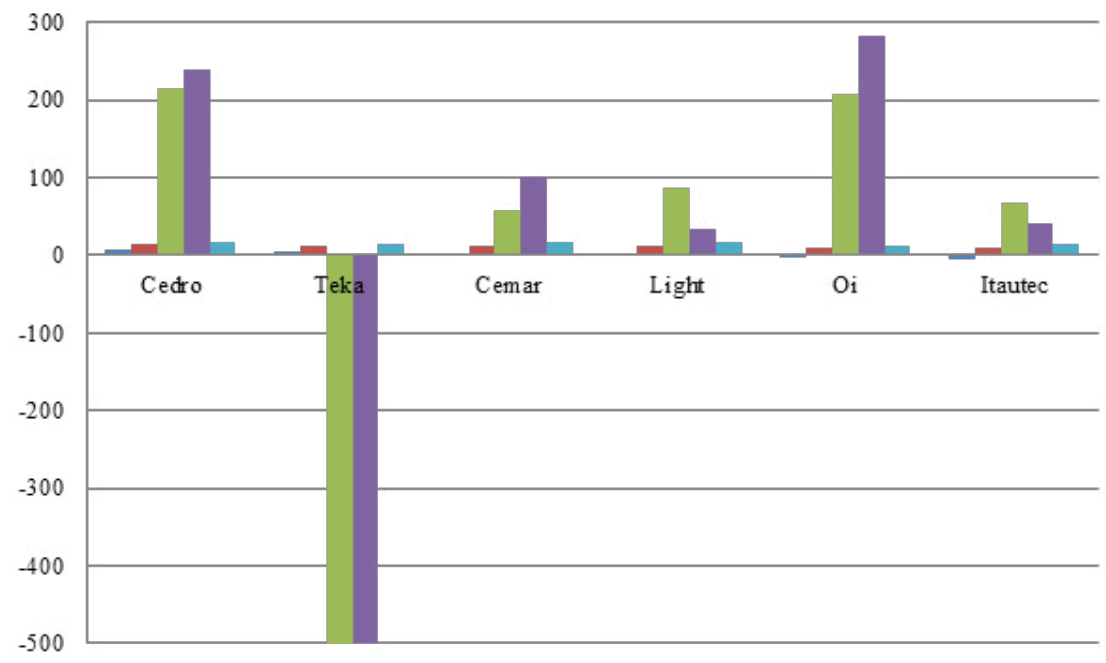

- Média de retomo realizado

Média de retorno estimado CAMP

Média de retomo estimado FF3F

- Média de retomo estimado FF5F

- Média de retorno estimado CAMP risco-Brasil

Cabe ressaltar, ainda, que os modelos de precificação de três e cinco fatores estimaram valores muito superiores aos retornos médios realizados, causando a frustação dos acionistas que adoram esses modelos para auxiliar na tomada de decisão de quais empresas investirem. Já os modelos CAPM e CAPM com riscoBrasil definiram retornos inferiores comparados aos retornos realizados das empresas com maiores retornos, causando uma perda financeira aos investidores que não optaram por comprar ações dessas empresas por julgarem seus retornos baixos, conforme resultados obtidos nesses modelos. Assim, conclui-se que os modelos de precificação, embora tenham uma aceitação na literatura de finanças, não devem ser utilizados para orientação de compras de ações de forma isolada, visto que não conseguem precificar com eficácia os retornos das ações.

Analisando as variações calculadas para identificar se o retorno realizado ocorreu conforme os retornos estimados por cada modelo, por um lado, a maior variação positiva foi de 1.066,12\% ao empregar o modelo CAPM, ou seja, o retorno efetivado foi superior em mais de 1000 vezes ao calculado pelo modelo. Por outro lado, encontrou-se um valor de variação negativa de aproximadamente $150 \%$, cujo resultado indica que o retorno efetivado foi inferior 150 vezes ao valor estimado empregando o mesmo modelo, o que evidencia mais uma vez a sua deficiência para tal finalidade.

Por fim, o modelo de precificação com o riscoBrasil foi o que apresentou a menor variação positiva e negativa, de 4,52\% e -3,27, respectivamente. Essas variações informam que o retorno efetivado foi 4,52 vezes superior ao estimado e 3,27 vezes inferior ao retorno estimado. Apesar de o modelo CAPM com riscoBrasil possuir uma maior quantidade de resultados estimados próximos aos retornos efetivados para as empresas analisadas, as variações determinadas por esse modelo se mostram bem dispersas, conforme Gráfico 5. Assim, seu emprego com o objetivo de precificar os retornos das ações deve ser utilizado com cautela e em conjunto com outras ferramentas que auxiliem o acionista no processo decisório de investimentos em renda variável.

\section{Conclusões}

Nesse trabalho, empregaram-se os diferentes modelos de precificação de ativos (CAPM, FF3F, FF5F e CAPM com riscoBrasil) para analisar se eles conseguem estimar os retornos das ações das empresas de capital aberto no Brasil e, consequentemente, se podem ser utilizados como apoio à tomada de decisão em investimentos em renda variável.

Para alcançar o objetivo, foram analisados os retornos efetivados de 60 empresas listadas na B3 no período de 2000 a 2018. A análise foi efetuada a partir do cálculo das variações entre os retornos realizados e estimados por cada modelo.

Os resultados da pesquisa indicam que os modelos não foram satisfatórios como ferramenta de precificação de ativos, visto que os valores obtidos apresentam grandes dispersões. Nos modelos de três e cinco fatores, foram observados resultados muito superiores aos retornos das ações (valores reais). Já nos modelos CAPM e CAPM com riscoBrasil observa-se uma grande variabilidade dos resultados, reduzindo a confiabilidade dos modelos. É evidente que os modelos são limitados e, apesar de inclusões de novas variáveis, não conseguem estimar corretamente os retornos das ações. 
O mercado de renda variável é influenciado por diversos fatores econômicos, endógenos e exógenos a empresas, e dificilmente um modelo de precificação poderia ser representado em sua totalidade por todas essas variáveis que expliquem o retorno das ações. A tentativa de desenvolver modelos que tentem representar as variações do mercado e indicar seus possíveis resultados é de grande valia, mas o desenvolvimento desses modelos e a sua aplicação com resultados precisos são muito complexos.

Conclui-se, portanto, que os modelos servem apenas de base teórica na literatura de finanças e que a tomada de decisão baseada apenas nos seus resultados pode acarretar em ações equivocadas. É necessário que o investidor busque alternativas, além de conhecimento mais amplo, para uma decisão mais assertiva frente ao mercado acionário e suas inúmeras opções de investimento. Além disso, é extremamente importante que o investidor diversifique seus investimentos para minimizar os riscos envolvidos nesse tipo de negócio.

\section{Referências}

Argolo, E. F. B., Leal, R. P. C., \& Almeida, V. S. (2012). O modelo de Fama e French é aplicável no Brasil? Rio de Janeiro: UFRJ /COPPEAD.

Assaf Neto, A., \& Lima, F. G. (2014). Curso de administração financeira (3a ed.). São Paulo: Atlas.

Brasil Bolsa Balcão [B3]. (2019). Quantitativo de investidores na bolsa de valores. Link

Brasil. Ministério da Economia. (2019). Notícias sobre o tesouro direto. Link

Bajpai, S., \& Sharma, A. K. (2015). An empirical testing of capital asset pricing model in India. Procedia - Social and Behavioral Sciences, 189, 259-265. DOI: 10.1016/j.sbspro.2015.03.221

Black, F., Jensen, M. C., \& Scholes, M. (1972). The capital asset pricing model: Some empirical tests, in studies in the theory of capital markets. In M C. Jensen, Studies in the theory of capital markets (pp.79-121). New York: Praeger.

Cervo, A. L., \& Bervian, P. A. (2007). Metodologia científica (6a ed.). São Paulo: Pearson Prentice Hall.

Cunha, M. F. (2011). Avaliação de empresa no Brasil pelo fluxo de caixa descontado: Evidencias empíricas sob o ponto de vista do desempenho econômico-financeiro. (Tese de Doutorado, Faculdade de Economia, Administração e Contabilidade de São Paulo - FEA/USP). Link

Damodaran, A. (2012). Investment valuation: Tools and techniques for determining the value of any asset. (3a ed.) Nova Jersey, EUA: Wiley Finance.

D’Avila, M. (2019). Bolsa e tesouro direto alcançam juntos marca de 1 milhão de investidores. Link

Fama, E. F., \& French, K. R. (1992). The cross-section of expected stock returns. Journal of Finance, 47(2), 427465. DOI: 10.1111/j.1540-6261.1992.tb04398.x

Fama, E. F., \& French, K. R. (1993). Common risk factors in the returns on stocks and bonds. Journal of Financial Economics, 33(1), 3-56. DOI: 10.1016/0304-405X(93)90023-5

Fama, E. F., \& French, K. R. (2015a). A five-factor asset pricing model. Journal of Financial Economics, 116(1), 1-22. DOI: 10.1016/j.jfineco.2014.10.010

Fama, E. F., \& French, K. R. (2015b). International tests of a five-factor asset pricing model. Fama-Miller Working Paper, Tuck School of Business Working Paper n. 2622782. DOI: 10.2139/ssrn.2622782

Instituto Assaf. (2019). Indicadores e demonstrações financeiras: Indicadores da economia. Link

Lakonishok, J., \& Shapiro, A. (1986). Systematic risk, total risk and size as determinants of stock market returns. Journal of Banking and Finance, 10(1), 115-132.

Malaga, F. K., \& Securato, J. R. (2004). Aplicação do modelo de três fatores de Fama e French no mercado acionário brasileiro: um estudo empírico do período 1995-2003. Trabalho apresentado no vigésimo oitavo Encontro Anual 
da Associação Nacional de Programas de Pós-Graduação em Administração, Curitiba, Brasil. Link

Martins, C. C., \& Eid, W. Júnior. (2015). Pricing assets with Fama and French 5-factor model: A Brazilian market novelty. Trabalho apresentado no quinto Encontro Brasileiro de Finanças, São Paulo, Brasil. Link

Miralles-Quirós, M. D. M., Miralles-Quirós, J. L., \& Gonçalves, L. M. V. (2017). Testing the efficiency-CAPM joint hypothesis in the Bovespa. Revista de Gestão, Finanças e Contabilidade, 7(3), 414-435.

Noda, R. F., Martelanc, R., \& Kayo, E. K. (2016). O Fator de risco lucro/preço em modelos de precificação de ativos financeiros. Revista de contabilidade financeira - USP, 27(70), 67-79. DOI: 10.1590/1808-057x201412060

Nyangara, M., Nyangara, D., Ndlovu, G., \& Tyavambiza, T. (2016). An empirical test of the validity of the capital asset pricing model on the Zimbabwe Stock Exchange. International journal of economics and financial issues, 6(2), 365-379.

Rayes, A. C. R. W., Araújo, G. S., \& Barbedo, C. H. S. (2012). O modelo de 3 fatores de Fama e French ainda explica os retornos no mercado acionário brasileiro? Revista Alcance - Eletrônica, 19(1), 52-61.

Rogers, P., \& Securato, J. R. (2009). Estudo comparativo no mercado brasileiro do Capital Asset Pricing Model (CAPM), modelo 3-fatores de Fama e French e reward beta approach. RAC-Eletrônica, 3(1), 159-179.

Scott, W. R. (2009). Financial accounting theory (5a ed.). Toronto, Ontario: Pearson Education Canada.

Sharpe, W. F. (1964). Capital asset prices: A theory of market equilibrium under conditions of risk. Journal of Finance, 19(3), 425-443. DOI: $10.2307 / 2977928$

Silva, W. A. M., Trindade, J. A. S., Nagib, L. R. C., \& Reina, D. (2017). O Efeito do CAPM em relação ao retorno das ações das empresas listadas no novo mercado do BM\&FBovespa. Revista de Gestão, Finanças e Contabilidade, 7(3), 299-313.

Soranco, D., Cruz, J. A. W., Zanin, S., \& Rocha, D. T. (2013). Precificação de ativos baseado no modelo Capital Asset Pricing Model (CAPM). Pensar Contábil, 15(58), 24-31.

Stambaugh, R. (1982). On the exclusion of assets from tests of the two-parameter model: A sensitivity analysis, Journal of Financial Economics, 10(3), 237-268. DOI: 10.1016/0304-405X(82)90002-2

Vieira, M. D. V, Maia, V. M., Klotzle, M. C., \& Figueiredo, A. C. (2017). Modelo de cinco fatores de risco: Precificando carteiras setoriais no mercado acionário brasileiro. Revista Catarinense da Ciência Contábil, 16(48), 86-104. DOI: 10.16930/2237-7662/rccc.v16n48.2376

\section{Contato:}

Kascilene Gonçalves Machado

E-mail: kascilene.machado@ufj.edu.br 